\title{
Iron Phthalocyanine Knitted Polymers as Electrocatalysts for the Oxygen Reduction Reaction
}

\author{
Antonio Valverde-González, ${ }^{\mathrm{a}}$ Li Zhi Guan, ${ }^{\mathrm{b}}$ M. Luisa Ferrer, ${ }^{\mathrm{b}}$ Marta Iglesias, ${ }^{\mathrm{a}}$ Eva M Maya ${ }^{\mathrm{a}}$ \\ ${ }^{\mathrm{a}}$ Multifunctional and Supramolecular Materials Group and ${ }^{\mathrm{b}}$ Group of Bioinspired Materials, Instituto de Ciencia de Materia- \\ les de Madrid-ICMM, Consejo Superior de Investigaciones Cientificas-CSIC, c/ Sor Juana Ines de la Cruz 3, Cantoblanco, \\ Marid 28049, Spain.
}

\section{KEYWORDS. Iron (II) phthalocyanine, knitting porous polymer, electrocatalyst, oxygen reduction reaction}

\begin{abstract}
Knitted iron phthalocyanine based porous polymer networks (K-FePcs) were prepared in a single step using solvent knitting strategies with commercial iron phthalocyanine as building monomer. The incorporation of different aryl co-monomers (biphenyl and 1,2,4,5-tetraphenylbenzene) to FePc allowed quantitative yields, high porosities and excellent ORR activity. The reversible $\mathrm{Fe}(\mathrm{III}) / \mathrm{Fe}$ (II) redox potential of $\mathrm{FeN}_{4}$ centers of the knitted polymer networks in $\mathrm{N}_{2}$ saturated electrolyte solution (i.e. ca. $0.8 \mathrm{~V}$ vs RHE) were shown as good descriptors of their ORR activity. K-FePc2Ph presented the highest amount of FeN4 active sites and an adequate degree of steric hindrance to maintain the isolation between catalytically active sites. Moreover, it displayed comparable current density limits, and superior mass activity and half-wave potential (i.e. $0.88 \mathrm{~V} v s \mathrm{RHE}$ ) than those of $20 \% \mathrm{Pt} / \mathrm{C}$ benchmark catalyst, while keeping higher stability towards methanol oxidation. K-FePc2Ph can be an interesting alternative to Pt based ORR electrocatalysts.
\end{abstract}

\section{INTRODUCTION}

Over the past years, numerous attempts to replace platinumbased electrocatalysts for the oxygen reduction reaction (ORR) on the cathodes of fuel cells have been made. For instance, high temperature pyrolytic approaches rendered highly active, non-noble metal $(\mathrm{M})$ catalytic $\mathrm{MN}_{\mathrm{x}} \mathrm{C}$ centers, although these synthetic methods lack the accurate atomic control to replicate specific monodisperse metal coordination environments and availability. ${ }^{1-4}$ More recently, research has focused on the development of more sustainable nitrogen rich biomimetic macrocycles with adjusted $\mathrm{FeN}_{4} \mathrm{C}$ centers, as they are considered one of the most active sites for this reaction. ${ }^{5-8}$ Among them, iron phthalocyanines (FePcs) have been found particularly suitable as low cost non-precious electrocatalysts for ORR due to their ability to perform the reaction through a direct four-electron pathway from very low overpotentials.' Yet, FePc's poor intermolecular conductivity, which hampers the necessary electron transfer processes, and its lack of electrochemical stability difficult their application. Moreover, selfaggregation of Pc reduces the intermetallic distance and $\mathrm{O}_{2}$ accessibility, slowing the electron transfer properties for the ORR. The incorporation of different Pcs on the surface of conductive materials, such us porous carbons, carbon nanotubes or reduced graphene can greatly diminish these drawbacks and they have been extensively studied. ${ }^{10-14}$ The coupling of different tetrafunctionalized phthalocyanines pioneered in the preparation of conjugated 3D microporous polymers with elevated surface areas and outstanding catalytic activity towards ORR. ${ }^{15-17}$ Nevertheless, the use of precious metals and the need of previous functionalization of the Pc precursors (involving several synthetic steps) limit their practical use.

Knitting strategies have been well established to yield hypercross-linked porous aryl polymers from cheap and accessible aromatic monomers. ${ }^{18,19}$ More recently, this approach has been extended towards the use of metal complexes as monomers, where the coordination environment of the final polymer network was preserved. ${ }^{20,21}$ Furthermore, the capability of using different aromatic co-monomers can provide higher degree of steric hindrance maintaining isolation between catalytically active sites.

In this work, the solvent knitting strategy has been used to prepare, for the first time; iron phthalocyanine (FePc) based porous knitted polymer networks from commercial unfunctionalized FePc in quantitative yields, as a new generation of non-pyrolyzed, non-noble metal ORR electrocatalysts. This strategy allows obtaining porous and robust networks in a single synthetic step without using a pre-functionalized phthalocyanine as previously reported for other Pc-containing porous networks.

Either by using Friedel-Crafts reaction, with $-\mathrm{CH}_{2}$ - spacers from the external cross-linker such as dimethoxymethane, ${ }^{18}$ or by using Scholl reaction, through aryl-aryl couplings, ${ }^{19}$ we were able to prepare structurally different knitted FePc polymer networks (Scheme 1). Thus, the new polymers exhibit diverse chemical composition, different thermal and porous properties but preserved FePc redox properties and activity towards ORR, while improving the stability. 


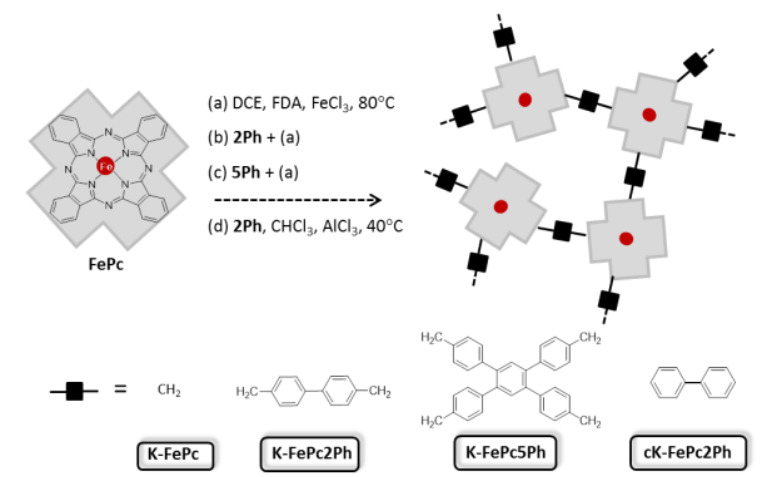

Scheme 1. Synthetic strategy for knitted FePcs porous networks with different linkers

\section{MATERIALS AND METHODS Materials}

Iron (II) phthalocyanine (FePc) was purchased from TCI with a purity $>98 \%$; Biphenyl $(2 \mathrm{Ph})$ was supplied by Fluka with a purity $>98 \%$; Anhydrous $\mathrm{FeCl}_{3}$ was purchased from Alfa Aesar with $98 \%$ of purity; Anhydrous $\mathrm{AlCl}_{3}$ and dichloroethane (DCE) (extra dry) were supplied by Across Organics with purities $>98.5 \%$ and $>99.8 \%$ respectively. Formaldehyde dimethyl acetal (FDA) and solvents were supplied by Aldrich with analytical grade. 1,2,4,5-tetraphenylbenzene $(5 \mathrm{Ph})$ was synthetized according with the procedure reported. ${ }^{22}$ For conductive ink preparation Nafion 117 (5\% solution in alcohols) was purchased from Aldrich while carbon black super P (CB) was from Alpha Aesar .

\section{Polymer Synthesis}

K-FePc: A solution of $0.200 \mathrm{~g}(0.35 \mathrm{mmol})$ of iron phthalocyanine in $15 \mathrm{~mL}$ of anhydrous dichloroethane was placed in a Schlenk and purged with nitrogen over $20 \mathrm{~min}$. Then, 3.5 mmol of formaldehyde dimethyl acetal (FDA) and $3.5 \mathrm{mmol}$ of $\mathrm{FeCl}_{3}$ were carefully added. The mixture was stirred for 48 $\mathrm{h}$ at $80^{\circ} \mathrm{C}$. The resulting dark green precipitate was collected by filtration and washed with ammonia under stirring for $4 \mathrm{~h}$ to remove unreacted $\mathrm{FeCl}_{3}$. Then, the suspension was neutralized with $\mathrm{HCl}$ and after filtration, the green solid was washed with hot methanol for $24 \mathrm{~h}$. Finally, the polymer was washed with water and THF under stirring. A green product was obtained as fine powder and was dried at $80^{\circ} \mathrm{C}$ overnight. Yield: $40 \%$

K-FePc2Ph and K-FePc5Ph: A solution of $0.200 \mathrm{~g}(0.35$ $\mathrm{mmol}$ ) of iron phthalocyanine and $0.35 \mathrm{mmol}$ of biphenyl (for $\mathrm{K}-\mathrm{FePc} 2 \mathrm{Ph}$ ) or $0.35 \mathrm{mmol}$ of 1,2,4,5-tetraphenylbenzene (for $\mathrm{K}-\mathrm{FePc} 5 \mathrm{Ph}$ ) in $30 \mathrm{~mL}$ of anhydrous dichloroethane was placed in a Schlenk. The solution was purged with nitrogen over 20 min and then $3.5 \mathrm{mmol}$ of FDA and $3.5 \mathrm{mmol}$ of $\mathrm{FeCl}_{3}$ were carefully added. The mixture was stirred for $48 \mathrm{~h}$ at $80^{\circ} \mathrm{C}$. The resulting dark green precipitate was collected by filtration and washed following the same protocol described for K-FePc. Green solids were obtained in quantitative yields.

Conjugated knitting polymer cK-FePc2Ph: A solution of $0.200 \mathrm{~g}(0.35 \mathrm{mmol})$ of iron phthalocyanine and $0.35 \mathrm{mmol}$ of biphenyl in $10 \mathrm{~mL}$ of chloroform were placed in a Schlenk and purged with nitrogen over $20 \mathrm{~min}$. Then $2.5 \mathrm{mmol}$ of $\mathrm{AlCl}_{3}$ were carefully added and the mixture was stirred $48 \mathrm{~h}$ at $40^{\circ} \mathrm{C}$. The resulting dark green precipitate was collected by filtration and washed for $4 \mathrm{~h}$ with a solution of $\mathrm{HCl}$ in water $(4 \mathrm{~mL}$ of $\mathrm{HCl}$ in $50 \mathrm{~mL}$ of water), 12 hours with water and $1 \mathrm{~h}$ with
THF water under vigorous stirring. Green solid was obtained in quantitative yield.

\section{Characterization}

The solid-state ${ }^{13} \mathrm{C}$-NMR spectra were recorded in a Bruker $\mathrm{AV}-400-\mathrm{WB}$ using a $4 \mathrm{~mm}$ triple channel probe with $\mathrm{ZrO}$ rotors and Kel-F plug at room temperature and at $100.32 \mathrm{MHz}$. In all cases, the speed of rotation was set at $10 \mathrm{KHz}$. The spectra were collected using a spectral width of $35 \mathrm{kHz}$ and the chemical shift refers to the $\mathrm{CH}_{2}$ signal of adamantine (29.5 $\mathrm{ppm})$ as a secondary reference to TMS as the primary reference.

Fourier Transform Infrared Spectra (FT-IR) were recorded on Bruker IFS 66VS Spectrometer $\left(10.000-50 \mathrm{~cm}^{-1}\right)$.

Raman spectra were recorded at ambient conditions for a 785 $\mathrm{nm}$ laser excitation wavelength with a Renishaw invia Raman microscope. The exposure time was $10 \mathrm{~s}$ and 25 scans were accumulated. The power used was 5\% with grating time 1200 $1 / \mathrm{min}$ and optical microscope magnification of 50X.

Elemental Analyses were obtained with a LECO CHNS-932 elemental analyzer (C, H, N).

Iron content was determined by quantitative TXRF analysis using a benchtop S2 PicoFox TXRF spectrometer Bruker Nano (Germany) equipped with a multilayer monochromator with $80 \%$ of reflectivity at $17.5 \mathrm{keV}(\mathrm{Mo} \mathrm{K} \alpha$ ), a Mo X-ray source working at $50 \mathrm{kV}$ and $600 \mu \mathrm{A}$ and a XFlash SDD detector with an effective area of $30 \mathrm{~mm}^{2}$.

Nitrogen adsorption isotherms where measured at $77 \mathrm{~K}$ using a Micromeritics ASAP $2020 \mathrm{M}$ surface and porosity analyzer. Prior to measurement, the samples were degassed for $12 \mathrm{~h}$ at $130^{\circ} \mathrm{C}$. Specific surface areas were determined by BET technique and the pore size distribution by NLDFT methods.

Thermogravimetric analysis (TGA) data were obtained on a TA Q-500 analyzer under air atmosphere using around 4-5 mg of sample under a flow of $60 \mathrm{~mL} / \mathrm{min}$. The samples were heated from 50 to $850{ }^{\circ} \mathrm{C}$ at $10{ }^{\circ} \mathrm{C} / \mathrm{min}$.

Absorption spectra were carried out in a UV-VIS-NIR Varian Cary 500 Scan spectrophotometer.

Scanning electron microscopy (SEM) micrographs were obtained with a Hitachi SU-8000 microscope operating at 0.5 $\mathrm{kV}$. The samples were prepared by dispersing the powder onto a double-sided adhesive surface.

EDX-analysis was made in a FEI microscope NOVA NanoSEM 230 model equipped with an EDAX-Ametek detector, metalized by gold.

\section{Electrochemical Properties}

The catalyst ink dispersion was prepared by sonication for $30 \mathrm{~min}$ of $4 \mathrm{mg}$ of the Knitted polymer with $4 \mathrm{mg}$ Carbon black (Super P) into $500 \mu \mathrm{L}$ isopropanol solvent containing 34 $\mathrm{mg}$ of $5 \mathrm{wt} \%$ Nafion. Then, $8 \mu \mathrm{L}$ of the mixture were dropped onto a polished glassy carbon electrode $(5 \mathrm{~mm}$ in diameter). The loaded electrodes were placed in a $60{ }^{\circ} \mathrm{C}$ oven for $30 \mathrm{~min}$ to dry and then were left to cool down before testing. The corresponding catalyst loading was $0.16 \mathrm{mg} . \mathrm{cm}^{-2}$.

A typical three-electrode system was employed to evaluate the electrochemical properties of the as-prepared catalysts. Specifically, glassy carbon, $\mathrm{Pt}$ wire and $\mathrm{Ag} / \mathrm{AgCl}$ (in $3.5 \mathrm{M}$ $\mathrm{KCl}$ solution) were used as the working, counter and reference electrode, respectively. All potentials were referred to the reversible hydrogen electrode by applying Eq. 1 to the obtained Voltage $v s \mathrm{Ag} / \mathrm{AgCl}$ electrode. 
$\mathrm{V}_{\mathrm{RHE}}=\mathrm{V}_{\mathrm{Ag} / \mathrm{AgCl}}+0.205+0.059 \times \mathrm{pH}$

Eq.1

All electrochemical measurements, including cyclic voltammograms (CV), linear sweep voltammetry (LSV) and chronoamperometry, were performed using an Autolab PGSTAT302 $\mathrm{N}$ potentiostat at $25^{\circ} \mathrm{C}$ in $0.1 \mathrm{M} \mathrm{KOH}$ solutions, previously purged with either high purity nitrogen or oxygen for at least 1 hour. Both CV and LSV were recorded at $10 \mathrm{mVs}^{-1}$ scan rate and the potential window ranged from -0.9 to $0.1 \mathrm{~V}$ vs $\mathrm{Ag} / \mathrm{AgCl}(3.5 \mathrm{M} \mathrm{KCl})$. Chronoamperometry tests were performed at constant applied potential of $0.35 \mathrm{~V} v s \mathrm{Ag} / \mathrm{AgCl}(3.5$ $\mathrm{M} \mathrm{KCl}$ ) at $1600 \mathrm{rpm}$ in $\mathrm{O}_{2}$ saturated $0.1 \mathrm{M} \mathrm{KOH}$ were run to check. In long-term stability tests $i$ - $t$ curves were run for $20000 \mathrm{~s}$ while for methanol crossover studies methanol $(0.3$ M) was injected after running $1500 \mathrm{~s}$. Cycling stability was performed by continuously running $1000 \mathrm{CV}$ at $50 \mathrm{~V} / \mathrm{s}$. CVs in $\mathrm{N}_{2}$ saturated solution at $0 \mathrm{rpm}$ and LSVs in $\mathrm{O}_{2}$ at $1600 \mathrm{rpm}$ were recorded before and after the cycling.

To elaborate the Koutecky-Levich (KL) plots from equation 3 , rotating disk working electrodes (RDE) were scanned catodically at $10 \mathrm{mV} / \mathrm{s}$ with different rotation speeds (i.e. from 250 to $2000 \mathrm{rpm}$ )

$$
\begin{gathered}
\frac{1}{J}=\frac{1}{J_{K}}+\frac{1}{J_{L}} \quad \text { Eq. } 2 \\
\frac{1}{J}=\frac{1}{J_{K}}+\frac{v^{1 / 6}}{0.620 n F A C_{O_{2}} D_{O_{2}}{ }^{2 / 3}} \cdot \frac{1}{\omega^{1 / 2}}
\end{gathered}
$$

Eq. 3

where $\mathrm{J}, \mathrm{J}_{\mathrm{K}}$, and $\mathrm{J}_{\mathrm{L}}$ are, respectively, the measured, kinetic and diffusion limiting current densities, $v$ is the kinematic viscosity $\left(0.01004 \mathrm{~cm}^{2} \cdot \mathrm{s}^{-1}\right), \mathrm{n}$ is the number of transferred electrons in the ORR process; $F$ is the Faraday constant $\left(96485 \mathrm{C} \cdot \mathrm{mol}^{-1}\right)$; $\mathrm{A}$ is geometric surface area of the electrode; $C_{02}$ is the oxygen concentration in the electrolyte solution $\left(1.39 \cdot 10^{-3}\right.$ mol. $\left.\mathrm{L}^{-1}\right)$, $D_{O 2}$ is the diffusion coefficient of oxygen in the solution $\left(1.9 \cdot 10^{-5} \mathrm{~cm}^{2} \mathrm{~s}^{-1}\right) \omega$ is the angular rotation speed $\left(\mathrm{rad} . \mathrm{s}^{-1}\right)$. The mass activity was obtained by normalizing the kinetic current $\left(\mathrm{I}_{\mathrm{K}}\right)$ to the electrode mass. $I_{K}$ was derived by multiplying $\mathrm{J}_{\mathrm{K}}$ (obtained from the KL plot at $0.9 \mathrm{~V} v s$ RHE) by the geometric area of the glassy carbon electrode. All LSVs have been corrected to discard the influence of the double layer capacitance on the ORR performance by subtracting the LSV data measured in $\mathrm{N}_{2}$-saturated solution from those obtained in $\mathrm{O}_{2-}$ saturated.

Double layer capacitance $\mathrm{C}_{\mathrm{dl}}$ was calculated after recording different $\mathrm{CVs}$ at various scan rates at potentials where there is no Faradaic current. ${ }^{15-17}$ According to the Eq. $4 \mathrm{C}_{\mathrm{dl}}$ is calculated from the slope of the capacitive current vs $r$.

$\mathrm{C}_{\mathrm{dl}}=\mathrm{J} / \mathrm{r}$

Eq. 4

where $r$ is the scan rate. Electrochemically active surface area (ECSA) was calculated using the Eq. 5

$\mathrm{ECSA}=\mathrm{C}_{\mathrm{d} /} / \mathrm{C}_{\mathrm{s}}$ Eq. 5

where $\mathrm{C}_{\mathrm{s}}$ is the specific capacitance value for a flat standard with $1 \mathrm{~cm}^{2}$ of real surface area. A $40 \mu \mathrm{F} / \mathrm{cm}^{2}$ as the average value was taken ${ }^{15}$

\section{RESULTS AND DISCUSION}

Synthesis and characterization of iron phthalocyanine knitted polymers
Using standard solvent knitting conditions based on FriedelCrafts reaction, ${ }^{18} \mathrm{FePc}$ was firstly heated at $80{ }^{\circ} \mathrm{C}$ in DCE in presence of $\mathrm{FDA}$, as external linker, and using $\mathrm{FeCl}_{3}$ as catalyst to yield the knitting polymer K-FePc (Scheme 1) with a moderate $40 \%$ yield. The incorporation of a second aromatic monomer biphenyl, (2Ph) or 1,2,4,5-tetraphenylbenzene, $(5 \mathrm{Ph})$ in the reaction media, yielded this time the knitting copolymers K-FePc2Ph and K-FePc5Ph in quantitative yields. Finally, by using $\mathrm{FePc}$ and $2 \mathrm{Ph}$ under the Scholl reaction conditions, (i.e., $\mathrm{AlCl}_{3}$ as catalyst, chloroform as solvent and moderated temperature of $\left.40^{\circ} \mathrm{C}\right)^{19}$ a predominantly conjugated polymer network, cK-FePc2Ph, mainly based on direct arylaryl couplings, was formed as shown by solid-state ${ }^{13} \mathrm{C}-\mathrm{NMR}$ (Figure 1a) with the absence of the broad signal at $35 \mathrm{ppm}$. This signal corresponds to the aliphatic carbons from the linker (- $\mathrm{CH}_{2}-$ groups) and can be noticed in K-FePc2Ph and $\mathbf{K}$ FePc5Ph ${ }^{13}$ C-NMR spectra (Figure 1a). Moreover, all polymer networks showed the characteristic intense signals between 145 and $120 \mathrm{ppm}$ attributed to the imine and aromatic carbons.

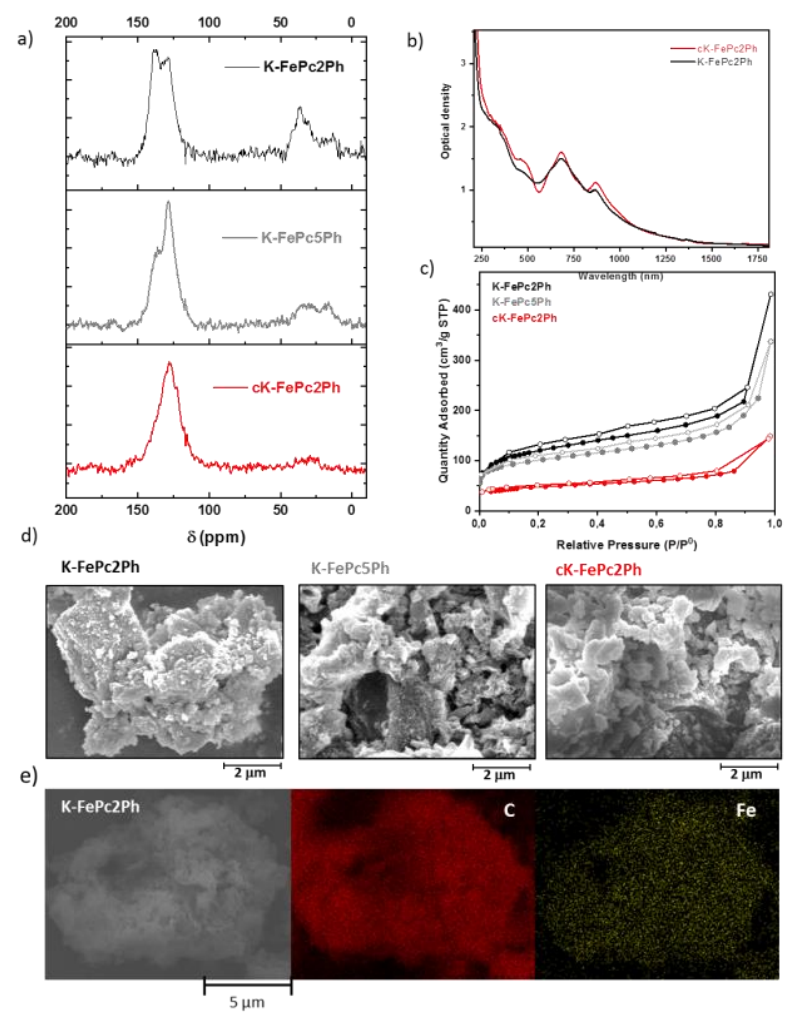

Figure 1. a) Solid state ${ }^{13} \mathrm{C}-\mathrm{NMR}$; b) UV-vis-NIR; d) $\mathrm{N}_{2}$ adsorption (full circles)/desorption (empty circles) isotherms and d) $\mathrm{SEM}$ image of K-FePc2Ph, K-FePc5Ph and cK-FePc2Ph; e) EDX analysis of $\mathrm{K}-\mathrm{FePc} 2 \mathrm{Ph}$, carbon (red), iron (yellow).

The presence of the FePc units was also confirmed by FT-IR (Figure S1), Raman spectroscopy (Figure S2) and UV-VisNIR spectroscopy (Figure 1b). Figure S1 shows the IR spectra of K-FePc2Ph compared with the original FePc monomer. The spectra show the five representative strong bands of the FePc ring at 1331, 1117, 1288, 1078 and $729 \mathrm{~cm}^{-1}, 23$ and a broad adsorption band between 1610 and $1720 \mathrm{~cm}^{-1}$ attributed to the biphenyl units as it was previously observed for knitted polymers prepared from $2 \mathrm{Ph}$ monomer. ${ }^{24}$ Raman spectra were recorded for all knitted polymers and FePc powder (Figure 
S2). All polymers contained the characteristic signals corresponding to FePc (Table S1) showing the preservation of the metal macrocycle. Additionally, two new bands assigned to the linker and aromatic monomer of the polymeric network appeared at ca. 1406 and $1446 \mathrm{~cm}^{-1}$ associated to $\mathrm{C}=\mathrm{CH}$ bending and to deformations of $\mathrm{C}-\mathrm{H}$ groups, respectively. The solid UV-VIS spectra (Figure 1b) of the K-FePcs2Ph polymer networks also confirmed the presence of the PcFe units with an intense $\mathrm{Q}$ band centered at $684 \mathrm{~nm}^{25}$

Chemical composition of the aromatic copolymer networks were analyzed by elemental analysis (EA) and total-reflection X-Ray Fluorescence (TXRF) and are shown in Table S2. For copolymers containing biphenyl, 1: 3 ratio, FePc: $2 \mathrm{Ph}$, were found while copolymer K-FePc5Ph showed a 1: 2 ratio, FePc: $5 \mathrm{Ph}$. The results revealed the lower reactivity of the iron complex monomer compared to the aromatic ones. In fact, as mentioned above, when FePc was used in the absence of aromatic linkers the corresponding K-FePc yield decreased drastically. Knitted copolymer networks exhibited iron contents between 4.4 and $6.6 \%$ with $\mathrm{N}$ : Fe ratio close to 8 suggesting the preservation of the FeN4 coordination center during the synthetic process.

TGAs showed high thermal stability with decomposition patterns in one-step for all polymers, as consequence of a high cross-linking degree (Figure S3). Nevertheless, a small decrease in thermal stability for K-FePc2Ph and K-FePc5Ph copolymers compared to the monomer was found due to presence of aliphatic linkers. The elimination of these units in $\mathbf{c K}$ FePc2Ph increased the thermal stability with a decomposition temperature of $350{ }^{\circ} \mathrm{C}$, further corroborating the absence of $\mathrm{CH}_{2}$ - linking units.

The morphology observed by SEM microscopy showed irregular particulate structures for the three co-polymers (Figure 1d and S4). However, mapping analysis for $\mathrm{Fe}$ and $\mathrm{C}$ elements by means of energy-dispersive X-ray (EDX) analysis, confirms the homogeneous dispersion of iron in the sample (Figure 1e and S5). The porous structure of the K-FePcs was evaluated by $\mathrm{N}_{2}$ adsorption-desorption isotherms at $77 \mathrm{~K}$ (Figure 1c) and the parameters are recorded in Table S3. The reduced surface area of ca. $62 \mathrm{~m}^{2} / \mathrm{g}$ for K-FePc homopolymer network suggested the low contribution of an extended polymer network $v s$ the external surface area. On the other hand, all co-polymer curves showed similar shape revealing the prevalence of microporous networks with a small contribution of certain mesoporosity. ${ }^{26}$ Specific surface areas of ca. 427,353 and $175 \mathrm{~m}^{2} \cdot \mathrm{g}$

${ }^{1}$ for K-FePc2Ph and K-FePc5Ph and cK-FePc2Ph, respectively, were within the range of those of other conjugated porous polymers based on functionalized phthalocyanines (118-580 $\left.\mathrm{m}^{2} \cdot \mathrm{g}^{-1}\right)^{15,16,27-30}$ Interestingly, the absence of $\mathrm{CH}_{2}$ linkers that reduced the flexibility of the structure in cKFePc2Ph, yielded lower surface area than the non-conjugated $\mathbf{K - F e P c 2 P h}$, which provided the highest surface area of the studied knitted polymer networks. The pore distributions, calculated by $\mathrm{N}_{2}$-DFT method (Figure S6), indicated a similar distribution of micro and mesopores for copolymers $\mathbf{K}$ FePc2Ph and K-FePc5Ph, which could proportionally allow better access to higher amount of active sites in the microporosity than $\mathbf{c K - F e P c 2 P h , ~ w h i c h ~ e s s e n t i a l l y ~ s h o w e d ~}$ mesopores.

\section{Electrocatalytic activity}

The ORR electrocatalytic performance for FePc monomer and K-FePc polymer networks was examined by CV after loading on the glassy carbon electrode a constant mass of ink containing FePc material, $\mathrm{CB}$ and Nafion $(\mathrm{C}$ as a binder. As increasing amounts of carbon material (i.e. up to 50\%) into the catalyst ink increases the electrical conductivity of the samples improving the local electron transfer, ${ }^{8,14}$ the amount of $\mathrm{CB}$ was set to $50 \%$. All samples showed a small reversible redox peak in $\mathrm{N}_{2}$ saturated electrolyte solution close to $0.8 \mathrm{~V}$ vs RHE (Figure 2a). This redox peak is associated to the Fe (III/II) redox potential of the FeN4 active site, which has been correlated to the $\mathrm{Fe}-\mathrm{O}_{2}$ binding energy, and considered as a descriptor for the ORR activity. ${ }^{8}$ Interestingly, K-FePc2Ph (the knitted polymer with highest surface area) resulted in the largest amount of accessible redox sites while the more conjugated and rigid polymer network, $\mathbf{c K}-\mathbf{F e P c 2 P h}$ with lower surface area, led to a less reversible $\mathrm{FeN}_{4}$ redox center regardless its relatively higher amount of iron content. a)

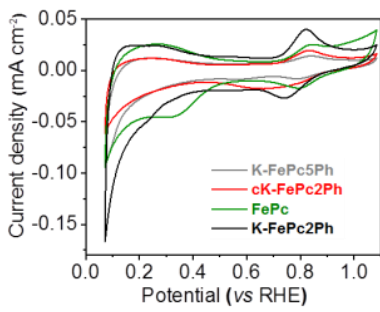

b)

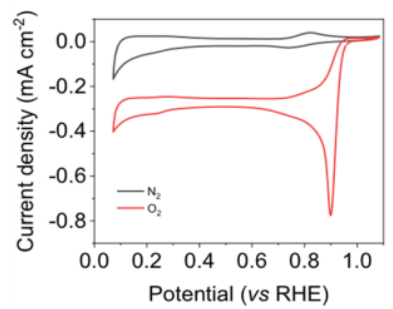

Figure 2. a) Cyclic voltammetry curves $(10 \mathrm{mV} / \mathrm{s})$ in $\mathrm{N}_{2}$ saturated $0.1 \mathrm{M} \mathrm{KOH}$ of the monomer FePc (green) and the knitted polymer networks, K-FePc2Ph (black) K-FePc5Ph (grey), cKFePc2Ph (red) mixed with $50 \mathrm{wt} \% \mathrm{CB}$; b) CVs of Knitted polymer K-FePc2Ph mixed with $50 \mathrm{wt} \% \mathrm{CB}$ in $\mathrm{N}_{2}$ - saturated $0.1 \mathrm{M}$ $\mathrm{KOH}$ (black) and $\mathrm{O}_{2}$-saturated $0.1 \mathrm{M} \mathrm{KOH}$ (red).

A pronounced cathodic signal in $\mathrm{O}_{2}$-saturated electrolyte (at ca. and $0.885,0.865,0.900$ and $0.902 \mathrm{~V} v s$ RHE) for KFePc2Ph, K-FePc5Ph, cK-FePc2Ph and FePc monomer respectively, revealed high electrocatalytic activity towards ORR (Figure 2b and S7) with very low overpotentials compared to the benchmark catalyst Pt 20\% (0.9112 vs RHE). It is worth mentioning that the absence of heat treatment after the polymerization helped the preservation of the coordination environment of the FeN4 centers. ${ }^{9,10}$

Linear sweep voltammetry (LSV) in $\mathrm{O}_{2}$ saturated $0.1 \mathrm{M} \mathrm{KOH}$ solution was used on a rotating disk electrode (RDE) to further analyze the K-FePc co-polymer electrocatalysts. In LSV, the ORR process is characterized by polarization curves holding flat plateau currents from which the limiting current density value $\left(\mathrm{J}_{\mathrm{L}}\right)$ and half-wave potential $\left(\mathrm{E}_{1 / 2}\right)$ can be obtained. Figure $3 \mathrm{a}$ compares the LSV curves of the monomer and $\mathrm{K}-\mathrm{FePc}$ polymer networks mixed with $50 \mathrm{wt} \% \mathrm{CB}$, to that of commercial (20 wt \%) Pt/C catalyst benchmark in $\mathrm{O}_{2}$ saturated $0.1 \mathrm{M}$ $\mathrm{KOH}$ solution, at a scan rate of $10 \mathrm{mV} / \mathrm{s}$ with a rotation speed of $1600 \mathrm{rpm}$. As it can be seen, all FePc samples exhibited similar high onset potential $\left(\mathrm{E}_{\text {onset }}\right)$ and very high $\mathrm{E}_{1 / 2}$ revealing how knitting of FePc into a 3D networks barely affects the potential at which ORR occurs (Table S4). In particular, the half-wave potential reached $0.88 \mathrm{~V}$ ( $v s \mathrm{RHE}$ ) for K-FePc2Ph, cK-FePc2Ph and FePc, which is $30 \mathrm{mV}$ higher than that of $20 \%$ 
Pt/C (i.e. $0.85 \mathrm{~V}$ vs RHE) showing their excellent ORR activity. Moreover, K-FePc2Ph displayed the highest $\mathrm{J}_{\mathrm{L}}$, close to that of Pt catalyst, in agreement with the reversible ORR descriptors showing the available $\mathrm{FeN}_{4}$ redox centers.
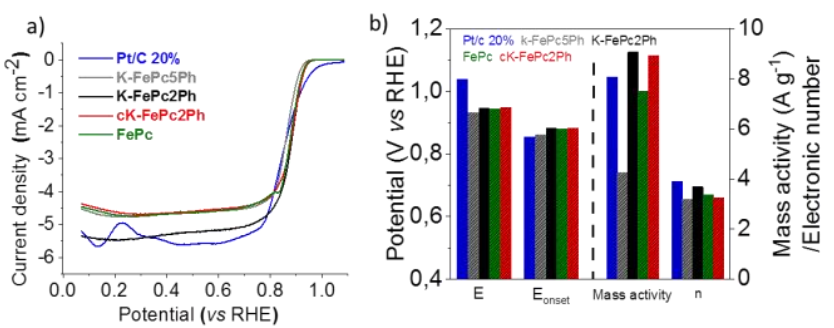

Figure 3. a) LSV curves of K-FePc2Ph, K-FePc5Ph, cKFePc2Ph, FePc and Pt/C (20\%) in $\mathrm{O}_{2}$-saturated $0.1 \mathrm{M} \mathrm{KOH}$ electrolyte at $1600 \mathrm{rpm}$. b) Comparisons of $\mathrm{E}_{\mathrm{ONSET}}, \mathrm{E}_{1 / 2}$ Mass activity and averaged number of electrons transferred in the ORR process for FePc monomer, K-FePc Knitted polymer networks and $20 \% \mathbf{P t} / \mathbf{C}$.

LSV curves at different rotation rates were also investigated to further assess the kinetics and the apparent number of electrons transferred during the $\mathrm{ORR}(n) . \mathrm{J}_{\mathrm{L}}$ significantly increased with the rotation rate, as high rotation speed improves $\mathrm{O}_{2}$ diffusion to the electrode surface (Figure 4a and Figure S8). $\mathrm{K}-\mathrm{L}$ plots of $\mathrm{K}-\mathrm{FePc}$ polymer networks derived from LSV curves, according to equations 2 and 3, displayed good linearity and parallelism, suggesting first-order reaction kinetics towards dissolved oxygen concentration (Figure $4 \mathrm{~b}$ and Figure S9).

The average number of electrons transferred in the ORR process (Table S4, Figure 3b) was calculated from the slope of K$\mathrm{L}$ curves for K-FePc5Ph, K-FePc2Ph, cK-FePc2Ph, FePc and $\mathbf{P t} / \mathbf{C}$. ${ }^{5}$ The achieved average $\mathrm{n}$ values for the knitted polymers K-FePc2Ph, K-FePc5Ph, cK-FePc2Ph and FePc monomer were $3.7,3.2,3.3$ and 3.4 , respectively. The results show that despite all knitted polymers have an important contribution of a 4-electron pathway, a coexistence of 2 e- and 4 e- reduction processes occur and therefore, some $\mathrm{H}_{2} \mathrm{O}_{2}$ production. Yet, K-FePc2Ph was the most efficient FePc polymer based catalyst. Related FePc based conjugated microporous polymers showed $\mathrm{n}$ values higher than 3.9 , with amounts of produced $\mathrm{H}_{2} \mathrm{O}_{2}$ below $5 \% .{ }^{15,16}$ The evaluated $\mathrm{n}$ at different voltages for K-FePc2Ph knitted polymer (from 3.62 to 3.72, Figure S10), suggests higher amounts of produced $\mathrm{H}_{2} \mathrm{O}_{2}$. For instance, conjugated $\mathrm{CoPc}$ based porous polymers having $\mathrm{n}$ values close to 3.6 produced $20 \%$ of $\mathrm{H}_{2} \mathrm{O}_{2}$. In our case, larger particles size or lower surface area (and active electrochemical surface area, see below), which worsen mass transportation towards catalytic sites, could decrease the $\mathrm{n}$ value. Compared to other non-pyrolyzed $\mathrm{MN}_{\mathrm{x}}$ coordination-frameworks, the new electrocatalyst showed superior activity ${ }^{31,32}$ whereas very close performance was found for phthalocyanine based conjugated microporous polymer approached via SonogashiraHagihara coupling reaction. ${ }^{15,16}$ While these conjugated porous polymers provided relevant insights on the efficiency of FePc centers in a polymer network with different spacers or combined with other metal centers (i.e Co, $\mathrm{Zn}$ ) thanks to their very controlled location of the $\mathrm{FeN}_{4}$ centers, our knitted polymer offered new cost efficient way to produce electrocatalysts. Moreover, low molecular weight FePc polymers and exfoliated amorphous conjugated FePcs polymers adsorbed on gra- phene ${ }^{14,17}$ were recently obtained exhibiting higher mass activities, and onset and half-wave potentials, in agreement with recent reports showing increased performance of nanostructured electrocatalysts on energy generation related reactions. ${ }^{35-}$ ${ }^{37}$ In all cases, the ultrathin surfaces allowed more exposed catalytic sites and easier mass transportation.

The accessibility to the catalytic sites through the porous network also influenced the ORR performance of knitted polymers. The active electrochemical surface area (ECSA) for KFePc2Ph electrodes (ca. $7.4 \mathrm{~m}^{2} / \mathrm{g}$ ) was estimated from its double layer capacitance (Figure S11). The results were in the range, but somewhat lower than those reported for conjugated porous phthalocyanines (i.e. $9-13 \mathrm{~m} / \mathrm{cm}^{2}$ ), whose ordered structure minimized bottle-neck sites. ${ }^{15,16}$ Nevertheless, FePc monomer, (i.e., with no linked co-monomer contribution that might alleviate partial self-aggregation) showed lower $\mathrm{J}_{\mathrm{L}}$ and mass activity at $0.9 \mathrm{~V}$ ( $v s$ RHE) than those knitted polymers containing a biphenyl group, i.e., K-FePc2Ph, cK-FePc2Ph (Figure 3a). On the other hand, the lower iron content resulting from the weighty character of $5 \mathrm{Ph} v s 2 \mathrm{Ph}$ reduced the mass activity in K-FePc5Ph, while the more rigid cK-FePc2Ph polymer network, with lower surface area, led to a less reversible $\mathrm{FeN}_{4}$ redox center, limiting the $\mathrm{J}_{\mathrm{L}}$. Therefore, an adequate linker should be carefully chosen to be bulky enough to maintain a proper intermetallic distance while providing high concentration of available $\mathrm{FeN}_{4}$ centers.

Besides the ORR activity, long term stability and fuel crossover (e.g. methanol) can greatly affect the overall performance of the cathode electrocatalysts, as it is seen for the $\mathrm{Pt} / \mathrm{C}$ benchmark. $^{33,34}$ Thus, we also evaluated the stability of $\mathbf{K}$ FePc2Ph with $50 \% \mathrm{CB}$ for methanol crossover by testing the chronoamperometric response at constant voltage of $-0.35 \mathrm{~V}$, in $\mathrm{O}_{2}$ saturated $0.1 \mathrm{M} \mathrm{KOH}$ electrolyte at $1600 \mathrm{rpm}$. The $i-t$ curves were then compared to those of $20 \% \mathrm{Pt} / \mathrm{C}$ catalyst and FePc monomer with $50 \%$ CB. K-FePc2Ph polymer network exhibited quite stable amperometric response after the addition of methanol at $1500 \mathrm{~s}$ showing its excellent stability towards methanol (Figure 4c). In contrast, a sharp drop of the current response of ca. $70 \%$ followed the introduction of methanol on the $20 \% \mathrm{Pt} / \mathrm{C}$ benchmark catalyst. Moreover, the knitted polymer K-FePc2Ph also showed improved stability during the electrocatalytic ORR process compared to FePc monomer just dispersed on $\mathrm{CB}$, where partial leaching of the FePc might arise. Long-term stability was further explored for K-FePc2Ph by continuously cycling the sample over 1000 times. LSV curves at $1600 \mathrm{rpm}$ in $\mathrm{O}_{2}$ saturated $0.1 \mathrm{M} \mathrm{KOH}$ solution performed before and after the test showed identical performance indicating negligible loss of activity (Figure 4d). Moreover, $\mathrm{CVs}$ in $\mathrm{N}_{2}$ saturated $0.1 \mathrm{M} \mathrm{KOH}$ solution, before and after the cycling were performed in order to control the active redox sites, with similar identical results indicating little damage has been made on the redox active centers (inset in Figure 4d). It should be noted, that longer i-t experiment (up to $20000 \mathrm{~s}$ ) showed some activity loss (ca. 17\%, Figure S12), but lower than that found for FePc conjugated porous polymers (29.9\%), and very close to $19.4 \%$ found for a mixed $\mathrm{FeCoPc}$ conjugated porous polymer. ${ }^{16}$ 

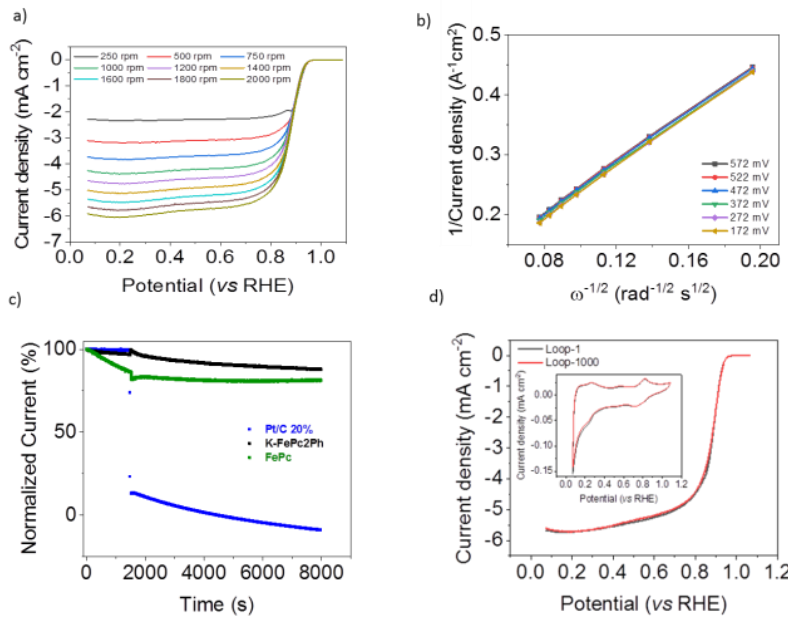

d)

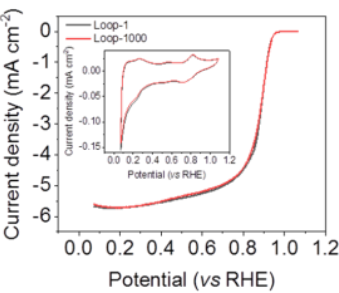

Figure 4. a) LSV curves of K-FePc2Ph at different rotation speeds from 250 to $2000 \mathrm{rpm}$; b) K-L plot of K-FePc2Ph; c) Amperometric $i-t$ curves of $\mathbf{F e P c}$ monomer, K-FePc2Ph, and $20 \% \mathbf{P t} / \mathbf{C}$ electrodes recorded at $1600 \mathrm{rpm}$ in $\mathrm{O}_{2}$-saturated $0.1 \mathrm{M}$ $\mathrm{KOH}$ solution d) Long term stability test of k-FePc2Ph: LSV performed in $\mathrm{O}_{2}$-saturated $0.1 \mathrm{M} \mathrm{KOH}$ solution at $1600 \mathrm{rpm}$ and $10 \mathrm{mV} / \mathrm{s}$ before and after cycling 1000 times (at 50mV/s) Inset: $\mathrm{CV}$ curves of $\mathrm{k}-\mathrm{FePc} 2 \mathrm{Ph}$ in $\mathrm{N}_{2}$-saturated $0.1 \mathrm{M} \mathrm{KOH}$ solution at 0 $\mathrm{rpm}$ and $10 \mathrm{mV} / \mathrm{s}$, before and after $1000 \mathrm{CV}$ cycles.

\section{CONCLUSIONS}

In conclusion, we successfully prepared, through a simple onepot knitting strategy, K-FePc polymer networks from commercial FePc, which result in highly efficient ORR electrocatalysts. The synthetic strategy allows preparing a new family of Pc-containing porous polymers in a very simple way without the need of Pc monomer pre-functionalization before polymerization. Pc-containing polymers with a wide variety of structures and different properties can be obtained by changing the co-monomer or crosslinking agent, while the ORR properties of FePc prevail. Among the evaluated polymer networks, KFePc2Ph demonstrated superior ORR activity showing the highest limiting current density, mass activity and half-wave overpotential. Additionally, compared to the commercial $20 \%$ $\mathrm{Pt} / \mathrm{C}$ benchmark catalyst, comparable $\mathrm{J}_{\mathrm{L}}$ and superior halfwave overpotential (i.e. $30 \mathrm{mV}$ ), mass activity and stability for methanol crossover were also found. These results are in agreement with the use of the reversible Fe (III/II) redox potential of the $\mathrm{FeN}_{4}$ centers as descriptors for the ORR activity of the new knitted polymer networks. Moreover, the knitting synthetic strategy might offer an interesting approach to get new non-pyrolytic, precious metal-free ORR polymer network electrocatalysts based on aromatic macrocycles with controlled $\mathrm{FeN}_{4} \mathrm{C}$ and carefully chosen co-monomer linkers capable to maintain an appropriate intermetallic distance while providing high concentration of available $\mathrm{FeN}_{4}$ centers.

\section{ASSOCIATED CONTENT}

\section{Supporting Information}

The Supporting Information is available free of charge on the ACS Publications website.

Tables S1-S4 contain structural characterization data and electrochemical data (pdf)

Figures S1 to S6 are characterization information: Raman, FT-IR, TGA, SEM and EDX analysis and Pore Distribution (pdf)
Figures S7-S12 contain information of electrochemical properties (pdf)

\section{AUTHOR INFORMATION}

\section{Corresponding Authors}

Eva M Maya eva.maya@csic.es

M. Luisa Ferrer mferrer@icmm.csic.es

Authors

Antonio Valverde González

Li Zhi Guan

Marta Iglesias

\section{Author Contributions}

A.V.G. and L.Z.G. contributed equally to this work

\section{ACKNOWLEDGMENTS}

Authors acknowledge to MINECO of Spain MAT2017-82288C2-2-P and RTI2018-097728-B-I00 projects for financial support. A. Valverde-González thanks Ministerio de Educación y Formación Profesional for FPU17/03463. L. Z. Guan also acknowledges Chinese Scholarship Council for a $\mathrm{PhD}$ research fellowship (CSC No.201608330266)

\section{REFERENCES}

(1) Wu, G; Zelenay, P. Nanostructured Non precious Metal Catalysts for Oxygen Reduction Reaction. Acc. Chem. Res. 2013, 46 (8), $1878-1889$.

(2) Martinez, U.; Babu, K.; Holby, E.F.; Chung, H.T.; Yin, X.; Zelenay, P. Progress in the Development of Fe-Based PGM-free Electrocatalysts for the Oxygen Reduction Reaction. Adv. Mater. 2019, 31, 1806545 .

(3) Zitolo, A.; Goellner, V.; Armel. V.; Sourgrati, M.; Mineva, T.; Stievano, L.; Fonda, E.; Jaouen. J. Identification of Catalytic Sites for Oxygen Reduction in Iron- and Nitrogen-Doped Graphene Materials. Nature Mater. 2015, 14, 937-942.

(4) Jiang, R.; Li, L.; Sheng, T.; Hu, G.; Chen, Y.; Edge-Site Engineering of Atomically Dispersed $\mathrm{Fe}-\mathrm{N}_{4}$ by Selective $\mathrm{C}-\mathrm{N}$ Bond Cleavage for Enhanced Oxygen Reduction Reaction Activities. J. Am. Chem. Soc. 2018, 140, 11594-11598.

(5) Zhang, W.; Lai, W.; Cao, R. Energy-Related Small Molecule Activation Reactions: Oxygen Reduction and Hydrogen and Oxygen Evolution Reactions Catalyzed by Porphyrin- and Corrole-Based Systems. Chem. Rev. 2017, 117(4), 3717-3797.

(6) Pegis, M.L.; Wise, C.F.; Martin, D.J.; Mayer, J.M. Oxygen Reduction by Homogeneous Molecular Catalysts and Electrocatalysts. Chem. Rev. 2018, 118(5), 2340-2391.

(7) Dey, S.; Mondal, B.; Chatterjee, S.; Rana, A.; Amanullah, S.; Dey, A. Molecular Electrocatalysts for the Oxygen Reduction Reaction. Nat. Rev. Chem. 2017, 1, 0098.

(8) Zagal, J. H.; Koper, M.T.M. Reactivity Descriptors for the Activity of Molecular $\mathrm{Mn}_{4}$ Catalysts for the Oxygen Reduction Reaction. Angew. Chem. Int. Ed. 2016, 55, $14510-14521$.

(9) Li, W.; Yu, A.; Higgins, D.C.; Llanos, B.G.; Chen, Z. Biologically Inspired Highly Durable Iron Phthalocyanine Catalysts for Oxygen Reduction Reaction in Polymer Electrolyte Membrane Fuel Cells. J. Am. Chem. Soc. 2010, 132, 17056-17058.

(10) Li, M.; Bo, X.; Zhang, Y.; Han, C.; Guo, L. Comparative Study on the Oxygen Reduction Reaction Electrocatalytic Activities of Iron Phthalocyanines Supported on Reduced Graphene Oxide, Mesoporous Carbon Vesicle, and Ordered Mesoporous Carbon. J. Power Sources 2014, 264, 114-122.

(11) Sun, C., Li, Z.; Yang, J.; Wang, S.; Zhong, X.; Wang, L. TwoDimensional Closely Packed Amide Polyphthalocyanine Iron Absorbed on Vulcan XC-72 as an Efficient Electrocatalyst for Oxygen 
Reduction Reaction Catal Today 2018, DOI: 10.1016/j.cattod.2018.01.029

(12) Morozan, A.; Campidelli, S.; Filoramo, A.; Jousselme, B.; Palacin, S. Catalytic Activity of Cobalt and Iron Phthalocyanines or Porphyrins Supported on Different Carbon Nanotubes Towards Oxygen Reduction Reaction. Carbon, 2011, 49, 4839-4847.

(13) Zhang, Z.; Dou, M.; Ji, J.; Wang, F. Phthalocyanine Tethered Iron Phthalocyanine on Graphitized Carbon Black as Superior Electrocatalyst for Oxygen Reduction Reaction. Nano Energy 2017, 34 $338-343$.

(14) Zhang, H.; Zhang, S.; Wang, Y.; Si, J.; Chen, Y.; Zhuang, L.; Chen, S. Boosting the Performance of Iron-Phthalocyanine as Cathode Electrocatalyst for Alkaline Polymer Fuel Cells Through EdgeClosed Conjugation. ACS Appl. Mater. Interfaces, 2018, 10 , 28664-28671.

(15) Liu, W.; Hou, Y.; Pan, H.; Liu, W.; Qi, D.; Wang, K.; Jiang, J.; Yao, X. Mixed Phthalocyanine-Porphyrin-Based Conjugated Microporous Polymers Towards Unveiling the Activity Origin of $\mathrm{Fe}-\mathrm{N}_{4}$ Catalysts for the Oxygen Reduction Reaction. J. Mater. Chem. A, 2018, 6, 22851-22857.

(16) Liu, W.; Wang, K.; Wang, Ch.; Liu, W.; Pan, H.; Xiang, Y.; Qi, D.; Jiang, J. An Ethynyl-Linked Fe/Co Heterometallic Phtalocyanine Conjugated Polymer for the Oxygen Reduction Reaction. $J$. Mater. Chem. A, 2018, 6, 8349-8357.

(17) Liu, W.; Wang, C.; Zhang, L.; Pan, H.; Liu, W.; Chen, J.; Yang, D.; Xiang, Y.; Wang, K.; Jiang, J.; Yao, X. Exfoliation of Amorphous Phthalocyanine Conjugated Polymers Into Ultrathin Nanosheets for Highly Efficient Oxygen Reduction. J. Mater. Chem. A, 2019, 7, 3112-3119.

(18) Li, B.; Gong, R.; Wang, W.; Huang, X.; Zhang, W.; Li, H.; Hu, C.; Tan, B. A New Strategy to Microporous Polymers: Knitting Rigid Aromatic Building Blocks by External Cross-Linker. Macromolecules 2011, 44, 8, 2410-2414.

(19) Msayib, K.J.; McKeown, N. B. Inexpensive Polyphenylene Network Polymers with Enhanced Microporosity. J. Mater. Chem. A, 2016, 4, 10110-10113.

(20) Valverde-González, A.; Marchal, G.; Maya, E.M.; Iglesias, M. A Step Forward in Solvent Knitting Strategy: Ruthenium and Gold Phosphine Complexes Polymerization Results in Effective Heterogenized Catalysts. Catal. Sci. Technol., 2019, 9, 4552-4560.

(21) Jiang, J.; Yoon, S. An Aluminum (III) Picket Fence Phtalocyanine-Based Heterogeneous Catalyst for Ring -Expansion Carbonylation of Epoxides J. Mater. Chem. A, 2019, 7, 6120-6125.

(22) Li, Z.H.; Wong, M.S.; Tao, Y. Two-Dimensional Oligoarylenes: Synthesis and Structure-Properties Relationships. Tetrahedron, 2005, 61, 5277-5285.

(23) Bayo, K.; Ouedraogo, G.V. UV-Visible and IR Spectra of Iron (II) Phthalocyanine Polymer Complexes Linked by bis-Pyridinato Ligands. Polyhedron, 1990, 9(8) 1087-1090.

(24) Maya, E. M.; Rangel-Rangel, E.; Díaz, U.; Iglesias, M. Efficient Cycloaddition of $\mathrm{CO}_{2}$ to Epoxides Using a Novel Heterogeneous Organocatalyst Based on Tetramethylguanidine-Porous Polyphenylene. J. $\mathrm{CO}_{2}$ Util., 2018, 25, 170-179.

(25) Peng, Y.; Cui, L.; Yang, S.; Fu, J.; Zheng, L.; Liao, Y.; Li, K.; Zuo, X.; Xi, D. Probing the Influence of the Conjugated Structure and Halogen Atoms of Poly-Iron-Phthalocyanine on the Oxygen Reduction Reaction by X-Ray Absorption Spectroscopy and Density Functional Theory. Electrochim. Acta, 2015, 154, 102-109.

(26) Thommes, M.; Kaneko, K.; Neimark, A.V.; Oliver, J.P.; Rodríguez-Reinoso, F.; Rouquerol, J.; Sing, K.S.W. Physisorption Gases, with Special Reference to the Evaluation of Surface Area and Pore Size Distribution (IUPAC Technical Report). Pure Appl. Chem. 2015, 9-10, 1051-1069.

(27) Tan, J.; Meeprasert, J.; Ding, Y.; Namuangruk, S.; Ding, X.; Wang, C.; Guo, J. Cyclomatrix Polyphosphazene Porous Networks with J-Aggregated Multiphthalocyanine Arrays for Dual-Modality Near-Infrared Photosensitizers. ACS Appl. Mater. Interfaces 2018, 10, 40132-40140.

(28) Cai, L.; Li, Y.; Li, Y.; Wang, H.; Yu, Y.; Liu, Y.; Duan, Q. Synthesis of Zinc phthalocyanine-Based Conjugated Microporous
Polymers with Rigid-Linker as Novel and Green Heterogeneous Photocatalysts. J. Hazard. Mater. 2018, 348, 47-55.

(29) Ding, X.; Han, B.-H. Copper Phthalocyanine-Based CMPs with Various Internal Structures and Functionalities. Chem. Commun., 2015, 51, 12783-12786.

(30) Neti, V. S. P. K.; Wang, J.; Deng, S.; Echegoyen, L. High and Selective $\mathrm{CO}_{2}$ Adsorption by a Phthalocyanine Nanoporous Polymer. J. Mater. Chem. A, 2015, 3, 10284-10288.

(31) Miner, E.; Fukushima, T.; Sheberla, D.; Sun, L.; Surendranath, Y.; Dinca, M. Electrochemical Oxygen Reduction Catalysed by $\mathrm{Ni}_{3}(\text { hexaiminotriphenylene) })_{2}$. Nat. Commun. 2016, 7, 10942.

(32) Huang, Z.H.; Xie, N.H.; Zhang, M.; Xu, B.Q. Nonpyrolyzed Fe@N Coordination-Based Iron Triazolate Framework: An Efficient and Stable Electrocatalyst for Oxygen Reduction Reaction. ChemSusChem 2016, 12, 200-207.

(33) Ren, C.; Li, H.; Li, R.; Xu, S.; Wei, D.; Kang, W.; Wang, L.; Jia, L.; Yang, B. Liu, J. Electrocatalytic Study of a 1,10-Phenantroline Cobalt(II) Metal Complex Catalyst Supported on Reduced Graphene Oxide Towards Oxygen Reduction Reaction. RSC Adv. 2016, 6, 33302-33307.

(34) Castillo-Blas, C.; López, N.; Gutierrez, M.C.; Ferrer, M.L.; Gándara, F.; Monge, M.A. Encoding Metal-Cation Arrangements in Metal-Organic Frameworks for Programming the Composition of Electrocatalytically Active Multimetal Oxides. J. Am Chem. Soc. 2019, 141(4) 1766-1774.

(35) Ren, X.; Zhou, J.; Qi, X. Liu, Y.; Huang, Z.; Li, Z.; Ge, Y.; Dhanabalan, S. C.; Joice Ponraj, S.; Wang, S.; Zhong, J.; Zhang H. Few Layers Black Phosphorus Nanosheets as Electrocatalysts for Highly Efficient Oxygen Evolution Reaction. Adv. Energy Mater. 2017, 7 (19), 1700396.

(36) Han, W.; Zhang, C.; Huang, Z.; Zhang, H.; Ren, L.; Qi, X.; Zhong, J. $\mathrm{TiO}_{2}$ nanoparticles and loading $\mathrm{MoS}_{2}$ nanosheets as Cocatalyst. Int. J. Hydrogen Energy 2014, 39 (34), 19502-19512.

(37) Zhang, Z.; Liu, Y.; Ren, L.; Zhang, H.; Huang, Z. Qi, X.; Wei, $\mathrm{X}$.; Zhong, J.; Three-dimensional networked Ni-Co-Se nanosheet/ nanowire arrays on carbon cloth, Electrochim. Acta, 2016, 200, 142151 


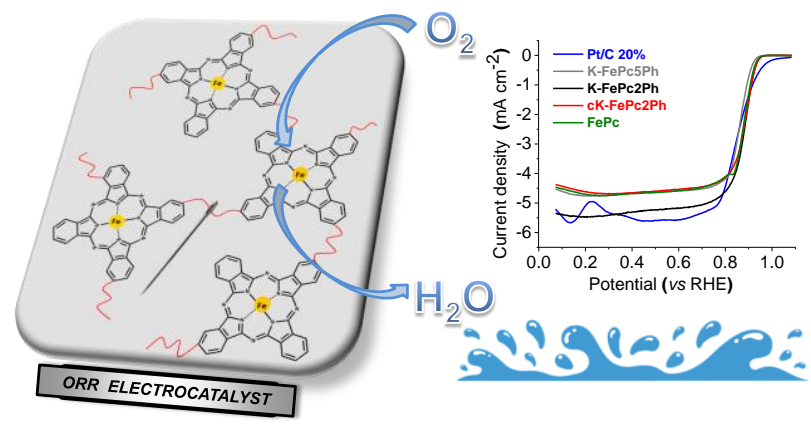

